\title{
On the Source of Transfer of Stereochemical Information in Ligands for Pd-Catalyzed AAA Reactions ${ }^{1}$
}

\author{
Barry M. Trost,* Jorge L. Zambrano, Wolfgang Richter \\ Department of Chemistry, Stanford University, Stanford, CA 94305-5080, USA \\ Fax +1650 7250002; E-mail: bmt@stanford.edu \\ Received 21 October 2000
}

\begin{abstract}
Examination of a series of ligands for a Pd-catalyzed asymmetric allylic alkylation (AAA) suggests the importance of buttressing effects for creating chiral space for high enantioselectivity.
\end{abstract}

Key words: asymmetric catalysis, palladium catalysis, allylic alkylation, desymmetrization of meso diol derivatives, chiral bis-phosphine ligands

Recent work in these laboratories have demonstrated the utility of ligands like $\mathbf{1}$ to generate Pd complexes for a wide of asymmetric allylic alkylations (AAA). ${ }^{1,2}$ Given that the coordination to $\mathrm{Pd}$ is via the phosphines which are quite remote from the source of chirality, i.e. the diaminocyclohexane, the question of how the chiral scaffold transmits stereochemical information to the reacting substrate becomes a major issue. In our working model, the ability of the chiral scaffold to influence the chiral space organized around the palladium in terms of the conformations of the triarylphosphino moiety is responsible for the molecular recognition. ${ }^{2}$ However, this model does not suggest a mechanism for the transmission of the stereochemical information. One thought involves a relay effect via steric interactions between the chiral scaffold and the benzoyl moiety that, in turn, influences the conformational biases of the triarylphosphino moiety. Indeed, the higher selectivity of the amide versus ester seems to support this suggestion. ${ }^{3}$ While the conformational biases of the ester and amide for a trans or anti orientation are similar, the shorter bond length of the amide brings the scaffold and the linker closer and thereby enhances their steric interactions. An additional factor considered the influence of the dihedral angle on the bite angle $\phi$ in the ligands 4 . Opening the dihedral angle should lead to also increasing the bite angle $\phi$ with a corresponding increase of interactions with the triarylphosphino moieties and the allyl fragments coordinated to $\mathrm{Pd}$. Indeed, ligands like the anthracenyl system $\mathbf{2}$ wherein the dihedral angle is quite large did give excellent results that seemed to be superior to the cyclohexyl system 1.3,4 Furthermore, the "inver-
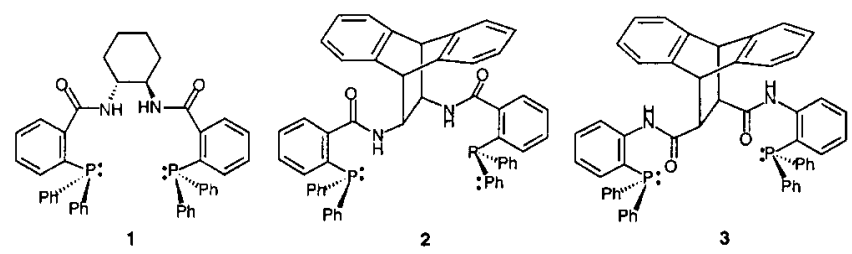

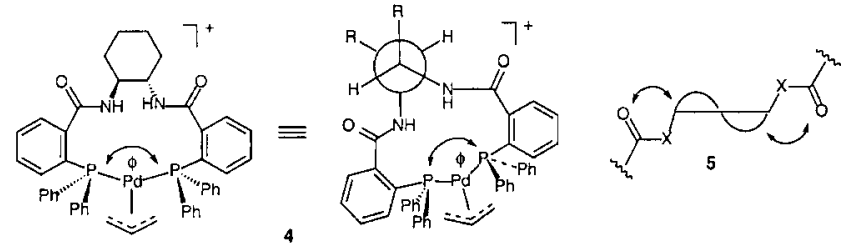

tomer" ligand $\mathbf{3}$ also gave excellent enantioselectivity but with the opposite sense of chirality. ${ }^{5} \mathrm{We}$, therefore, wanted to examine the role of the dihedral angle versus the more direct steric interactions which we refer to as "buttressing" effects as represented in $\mathbf{5}$.

We chose the desymmetrization of meso-diesters or urethanes, such as $\mathbf{6}$, as shown in eq. 1 as our test reaction since it removes uncertainties introduced in reactions involving the nucleophile in the enantiodiscriminating step. The formation of oxazolidin-2-one 7 has also proven to be useful for the synthesis of aminocyclopentitols as glycosidase inhibitors. ${ }^{6}$

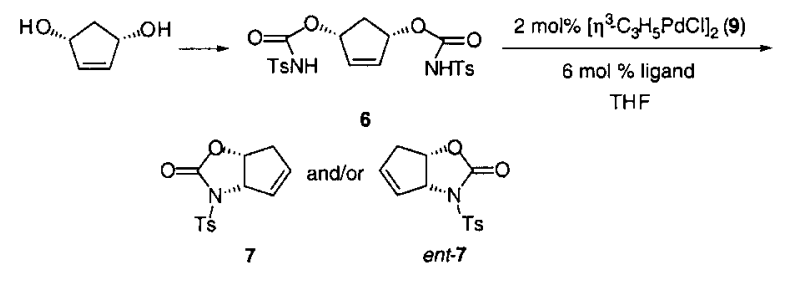

Our studies were initiated with the cyclopropane based ligand $\mathbf{8}$ that was prepared from the known acid $^{7}$ via the acid chloride $\left[(\mathrm{COCl})_{2}\right.$, cat. $\left.\mathrm{DMF}, \mathrm{CH}_{2} \mathrm{Cl}_{2}\right]$ and 2diphenylphosphinoaniline ${ }^{8}\left[\mathrm{C}_{5} \mathrm{H}_{5} \mathrm{~N}, \mathrm{CH}_{2} \mathrm{Cl}_{2}\right.$, r.t $]$. in $69 \%$ yield. Subjecting the bis-urethane 6 to a catalyst generated in situ by mixing $\pi$-allylpalladium chloride dimer (9) and ligand 8 in THF at r.t gave an excellent yield of 7 (92\%), but the ee was only $38 \%$ (see Table 1 , entry 2 ). This moderate ee is in striking contrast to the excellent ee using ligand 3 (Table 1 , entry 1 ). ${ }^{5}$ To ascertain the role of ring size, we also examined the four- (i.e. 10 $)^{9}$ and six- (i.e. 11) membered ring systems with similarly low ee's (Table 1 , entries 3 and 4). Eq 2 illustrates the synthesis of ligand $\mathbf{1 0 .}$ The cis-divinylcyclobutane was easily separated from the trans due to the facility of its thermal rearrangement.The direct oxidation of trans-1,2-divinylcyclobutane to the dicarboxylic acid, with $\mathrm{KMnO}_{4}$, proceeded in low yield; 
however, this convenient sequence can undoubtedly be improved. Thus, the differences between ligand $\mathbf{3}$ and ligands 8, 10, and 11 presumably do not derive from dihedral angles but rather from the steric bulk of the bicyclic framework of ligand $\mathbf{3}$.
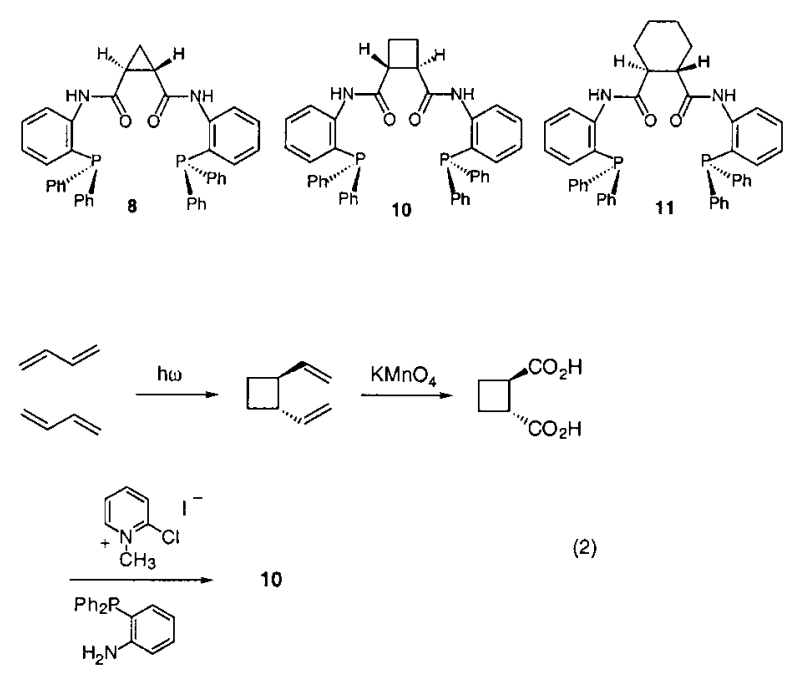

Table 1 Enantioselectivity of Oxazolidin-2-one Synthesis Using Invertomer Ligands (eq. 1) ${ }^{\mathrm{a}}$

\begin{tabular}{ccccc}
\hline Entry & Ligand & $\begin{array}{c}\text { Yield } \\
\text { 7/ent-7 }^{\mathrm{c}}\end{array}$ & ee $^{\mathrm{d}}$ & $\begin{array}{c}\text { er } \\
(\mathbf{7} / \text { ent }-\mathbf{7})\end{array}$ \\
\hline $1^{\mathrm{b}}$ & $\mathbf{3}$ & $99 \%$ & $88 \%$ & $94: 6$ \\
2 & $\mathbf{8}$ & $92 \%$ & $38 \%$ & $69: 31$ \\
$3^{\mathrm{c}}$ & $\mathbf{1 0}$ & N.D. & $39 \%$ & $30.5: 69.5$ \\
4 & $\mathbf{1 1}$ & $70 \%$ & $22 \%$ & $61: 39$ \\
5 & $\mathbf{1 2}$ & $96 \%$ & $54 \%$ & $23: 77$ \\
6 & $\mathbf{1 3}$ & $85 \%$ & $55 \%$ & $22.5: 77.5$ \\
7 & $\mathbf{1 4}$ & $75 \%$ & $54 \%$ & $23: 77$ \\
8 & $\mathbf{1 5}$ & $71 \%$ & $32 \%$ & $34: 66$ \\
9 & $\mathbf{1 6}$ & $89 \%$ & $46 \%$ & $27: 73$ \\
\hline
\end{tabular}

${ }^{a}$ In all cases, reactions were performed as shown in eq. 1 except if noted otherwise.

${ }^{\mathrm{b}}$ Taken from ref. 5 .

${ }^{\mathrm{c}}(\mathrm{dba})_{3} \cdot \mathrm{Pd}_{2} \mathrm{CHCl}_{2}$ used in lieu of 9 .

${ }^{\mathrm{d}}$ Isolated yields.

eDetermined by chiral HPLC using a Chiralpak AD column.

To dissect the contributions of the individual structural components present in ligand $\mathbf{3}$ for the asymmetric induction, ligands consisting of the core bicyclic framework, i.e. 12-14, were prepared from the corresponding diacids which are known enantiomerically pure in the first two cases. ${ }^{10,11}$ Since these ligands are of the opposite enantiomeric series compared to ligands $\mathbf{8}$ and 11, the major enantiomer observed was the opposite as noted in the er values. In the cases of ligands $\mathbf{1 2 - 1 4}$, a significant increase in ee occurred compared to the monocyclic system (Table 1, entries 5, 6 and 7 versus 2, 3, and 4), but no variation among the various bicyclic systems was observed. Surprisingly, saturating the double bond to give ligands $\mathbf{1 5}$ and $\mathbf{1 6}$ led to reactions with reduced ee (Table 1, entries 8 and 9). Interestingly, the ee using the bicyclo[2.2.2] ligand
16 was higher than that using the bicyclo[2.2.1] system. In this series, it is clear that the bulk of the dihydroanthracenyl system plays a major role in propagating the chirality over the long distances.
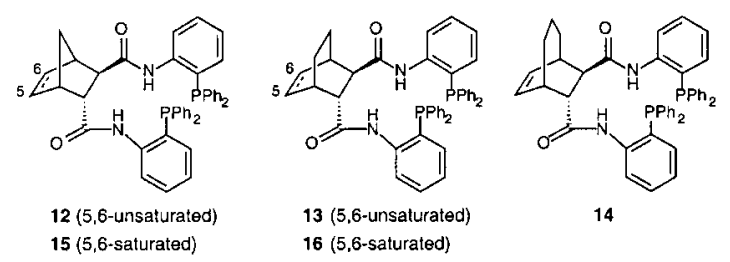

For comparison, we also examined the "normal" ligands in the bicyclic series, i.e. 17-21. The diamine precursors were obtained in $65-78 \%$ overall yield from the corresponding dicarboxylic acids by a standard Curtius sequence ${ }^{12}$ whereby the mixed anhydride $\left[\mathrm{ClCO}_{2} \mathrm{C}_{2} \mathrm{H}_{5}\right.$, $\left(\mathrm{C}_{2} \mathrm{H}_{5}\right)_{3} \mathrm{~N}, \mathrm{CH}_{3} \mathrm{COCH}_{3}$ ] was converted to the acyl azide $\left[\mathrm{NaN}_{3}, \mathrm{CH}_{3} \mathrm{COCH}_{3}, \mathrm{H}_{2} \mathrm{O}\right]$ followed by heating in toluene and acid hydrolysis. Table 2 summarizes the results. As expected, ${ }^{5}$ the normal series possessing the same absolute configuration as the invertomer series gives the products of opposite configuration, i.e. the $S$-enantiomer dominates with 17-21 but the $R$-enantiomer dominates with 12-16.
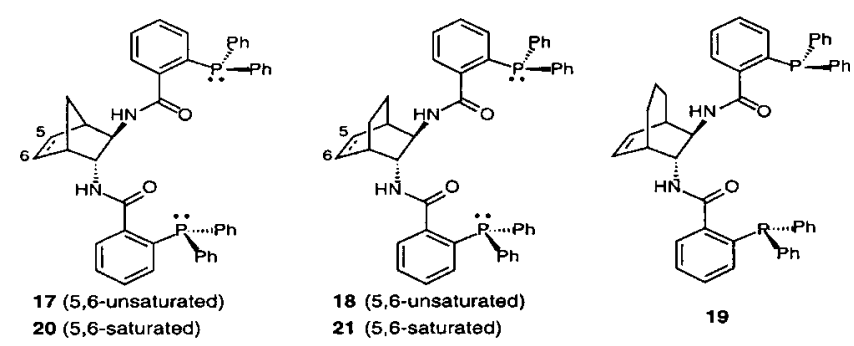

Clearly, there is a major difference in the manner in which the stereochemical information is propagated from the chiral scaffold to the chiral space. In this case, there is a clear trend of increasing ee in going from the [2.2.1] to [2.2.2] to [2.2.3] skeleta in both the unsaturated series (Table 2, entries 2-4) and saturated series (Table 2, entries 5 and 6). Furthermore, the additional steric bulk present in ligand 2 (Table 2, entry 1 ) does not increase the enantioselectivity compared to the bare [2.2.2] skeleton (Table 2, entries 3 and 6); in fact, there is the opposite effect with the ee being higher in the cases of ligands 18, 19 and 21.

Figure 1 shows the results of molecular modeling and focusing on the proximity of the binding domain to the bicyclic skeleton. The observed trends in ee do not follow the dihedral angles. On the other hand, using the angle $\mathrm{c}$ as a measure of the degree of the buttressing effect (the larger the angle, the greater the effect), there does appear to be a correlation. Thus, $\mathbf{1 9}$ gave the best ee and had the largest angle. Furthermore, 2, 18 and 21 all had similar results with 18, having the largest "buttress" angle, showing a marginally higher ee. 

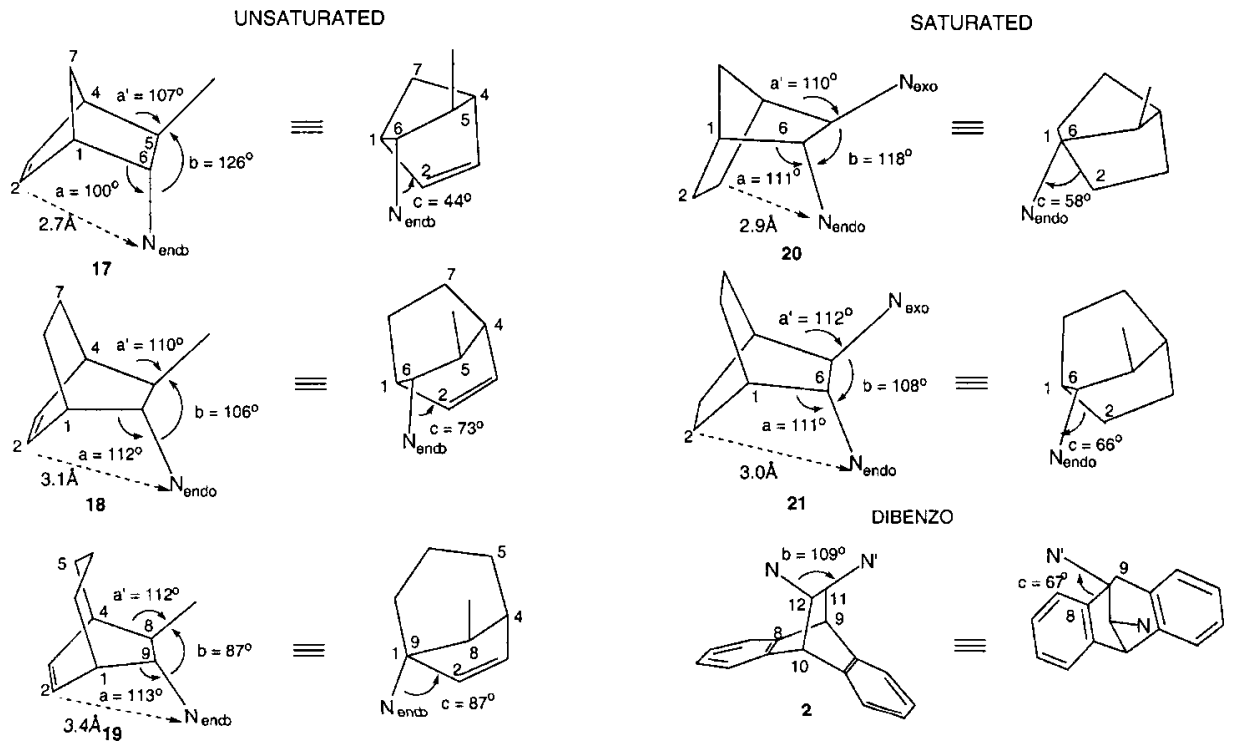

Figure 1 MM2 Calculations for bicyclic normal ligands

Table 2 Enantioselectivity of Oxazolidin-2-one Synthesis Using Normal Ligands (eq. 1) ${ }^{\mathrm{a}}$

\begin{tabular}{ccccc}
\hline Entry & Ligand & $\begin{array}{c}\text { Yield } \\
\text { 7/ent-7 }\end{array}$ & ee & $\begin{array}{c}\text { er } \\
\text { (7/ent-7) }\end{array}$ \\
\hline $1^{\mathrm{b}}$ & $\mathbf{2}$ & $94 \%$ & $88 \%$ & $94: 6$ \\
2 & $\mathbf{1 7}$ & $89 \%$ & $73 \%$ & $86.5: 13.5$ \\
3 & $\mathbf{1 8}$ & $\mathbf{7 4 \%}$ & $93 \%$ & $96.5: 3.5$ \\
4 & $\mathbf{1 9}$ & $69 \%$ & $96 \%$ & $98: 2$ \\
5 & $\mathbf{2 0}$ & $69 \%$ & $52 \%$ & $76: 24$ \\
6 & $\mathbf{2 1}$ & $69 \%$ & $91 \%$ & $95.5: 4.5$ \\
\hline
\end{tabular}

${ }^{a}$ In all cases, reactions were performed as shown in eq. 1 except if noted otherwise.

${ }^{\mathrm{b}}$ Taken from ref. $3 \mathrm{a}$.

Clearly, no single factor can explain the complex phenomenon involved in transferring stereochemical information over large distances in these ligands. Furthermore, the factors that are important in the normal series appear to be quite different than those mainly influencing the invertomer series. In the normal series, buttressing between the diphenylphosphinobenzoyl moiety and the chiral scaffold does appear to affect directly the ee and presumably the nature of the chiral pocket. Designing ligands to enhance this buttressing interaction then may create the next generation of chiral ligands for AAA reactions.

\section{Acknowledgement}

We thank the National Institutes of Health and the National Science Foundation for their generous support of our programs and the INTEVEP (Technological Venezuelan Institute of Petroleum) for a partial fellowship for J.L.Z. Financial support by the Feodor-Lynen Fellowship for W.R. is gratefully acknowledged. Mass spectra were obtained from the Mass Spectrometry Facility, University of San Francisco, supported by the NIH Division of Research Resources.

\section{References and Notes}

(1) For some recent references, see: Trost, B.M.; Surivet, J.-P. Angew. Chem. Int. Ed. 2000, 39, 3122. Trost, B.M.; Surivet, J.-P. J. Am. Chem. Soc. 2000, 122, 6291. Trost, B.M.;

Schroeder, G.M. J. Am. Chem. Soc. 2000, 122, 3785. Trost, B.M.; Tsui, H.-C.; Toste, F.D. J. Am. Chem. Soc. 2000, 122, 3534. Trost, B.M.; Schroeder, G.M. J. Org. Chem. 2000, 65, 1569.

(2) For reviews, see: Trost, B.M.; Lee, C.B. in "Catalytic Asymmetric Synthesis," Ojima, I., Ed.; Sec. Ed.; Wiley-VCH: New York, 2000, pp. 593-650. Trost, B.M.; Van Vranken, D.L. Chem. Rev. 1996, 96, 395. Trost, B.M. Acc. Chem. Res. 1996, 29, 355

(3) (a) Trost, B.M.; Van Vranken, D.L.; Bingel, C. J. Am. Chem. Soc. 1992, 114, 9327. (b) Trost, B.M.; Breit, B.; Organ, M.G. Tetrahedron Lett. 1994, 35, 5817.

(4) Also see: Trost, B.M.; Patterson, D.E. J. Org. Chem. 1998, 63, 1339.

(5) Trost, B.M.; Breit, B.; Peukert, S.; Zambrano, J.; Ziller, J.W. Angew. Chem. Int. Ed. Engl. 1995, 34, 2386.

(6) Trost, B.M.; Van Vranken, D.L. J. Am. Chem. Soc. 1993, 115, 444.

(7) Yamamoto, H.; Iwanaga, K.; Furuta, K. Org. Synth. 1989, 67, 76. Walborsky, M.H.; Sugita, T.; Inouye, Y. Tetrahedron 1964, 20, 1695 .

(8) Cooper, M.K.; Downes, J.M.; Duckworth, P.A.; Soucer, M.D.; Powell, R.J.; Kerby, M.C. Inorg. Synth. 1989, 25, 129.

(9) For the resolution of the dicarboxylic acid, see: Goldsworthy, L.J. J. Chem. Soc. 1924, 2013. For butadiene photodimerization, see: De Boer, C.D.; Turro, N.J.; Hammond, G.S. Org. Synth. Coll. Vol. V 1973, 528-532.

(10) Yamamoto, H.; Iwanaga, K.; Furuta, K. Tetrahedron Lett. 1986, 27, 4507.

(11) All new compounds have been satisfactorily characterized.

(12) Weinstock, J. J. Org. Chem. 1961, 26, 3511.

Article Identifier:

1437-2096,E;2001,0,SI,0907,0909,ftx,en;Y19700ST.pdf 